TECHNICAL TRANSACTIONS 5/2019

CHEMISTRY

DOI: $10.4467 / 2353737$ XCT.19.054.10578 SUBMISSION OF THE FINAL VERSION: 17/05/2019

\author{
Anna Rybak \\ Dawid Jankowski (iD) orcid.org/0000-0002-2013-0254 \\ jankowski@indy.chemia.pk.edu.pl \\ Chair of Chemical and Process Engineering, Faculty of Chemical Engineering \\ and Technology, Cracow University of Technology
}

\title{
THE HYDRODYNAMICS OF A FLUIDISED BED REACTOR
}

HYDRODYNAMIKA REAKTORA Z WARSTWĄ FLUIDALNĄ

\begin{abstract}
This article presents results concerning the hydrodynamics of a reactor with a porous fluidised bed (group D according to Geldart). Pressure drops were experimentally determined by gas flow through the bed and empty column. Using equations from literature flow resistance on the bed and gas distributor, critical velocity and terminal velocity were calculated and the obtained results were compared with experimental data. The equation which best described the work of the tested fluidised bed was identified through a process of trial and error. The influence of sieve being operated on pressure drops occurring during the process was determined and its applicability in the other conditions was verified.
\end{abstract}

Keywords: fluidisation, fluidised bed reactor, sieve plate, hydrodynamics

\section{Streszczenie}

W pracy zaprezentowano wyniki dotyczące hydrodynamiki reaktora z porolitową warstwą fluidalną (grupa D wg Geldarta). Eksperymentalnie wyznaczono spadki ciśnienia przy przeplywie gazu przez złoże i pustą kolumnę. Korzystając z równań literaturowych, obliczono opory przeplywu na złożu, dystrybutorze gazu, prędkość krytyczną i prędkość wywiewania oraz porównano otrzymane wyniki z danymi doświadczalnymi. Metodą prób i błędów znaleziono równanie najlepiej przedstawiające pracę badanego układu fluidalnego, określono wplyw eksploatowanego sita na spadki ciśnienia występujące $\mathrm{w}$ trakcie procesu oraz zweryfikowano jego stosowalność w innych warunkach.

Słowa kluczowe: fluidyzacja, reaktor fluidyzacyjny, sito, hydrodynamika 


\section{Nomenclature}

Ar - Archimedes number, -

$c_{D} \quad-$ drag coefficient, -

D - diameter of column, $m$

$d_{0} \quad$ - diameter of hole in the sieve bed, $\mathrm{m}$

$d_{p} \quad-$ diameter of a particle, $m$

$f^{p} \quad$ - ratio of cross-sectional area of the orifice to cross-sectional area of the distributor, -

$g \quad-$ acceleration of gravity, $\mathrm{m} \cdot \mathrm{s}^{-2}$

$H \quad$ - height of fluidised bed, $\mathrm{m}$

$H_{m f} \quad$ - height of fluidised bed at minimum fluidising conditions, $\mathrm{m}$

$H_{0} \quad$ - height of the stationary fluidised bed, $\mathrm{m}$

Ly - Laszczenka number, -

$n \quad-$ number of rotameter plots, -

$\Delta p \quad-$ pressure drop across the bed, $\mathrm{Pa}$

$\Delta p_{d}-$ pressure drop across a distributor, $\mathrm{Pa}$

$\Delta p_{m f}-$ pressure drop across the bed at minimum fluidising conditions, $\mathrm{Pa}$

$\mathrm{Re} \quad-$ Reynolds number, -

$\mathrm{Re}_{m f}-$ Reynolds number at minimum fluidising conditions, -

$\mathrm{Re}_{t}$ - Reynolds number at falling conditions, -

$S_{c z} \quad-$ area of particle, $\mathrm{m}^{2}$

$u \quad-$ gas velocity, $\mathrm{m} \cdot \mathrm{s}^{-1}$

$u_{m f} \quad-$ gas velocity at the minimum fluidising conditions, $\mathrm{m} \cdot \mathrm{s}^{-1}$

$u_{0} \quad-$ gas velocity through an orifice, $\mathrm{m} \cdot \mathrm{s}^{-1}$

$u_{o p} \quad-$ velocity of falling particle, $\mathrm{m} \cdot \mathrm{s}^{-1}$

$u_{t} \quad-$ terminal velocity, $\mathrm{m} \cdot \mathrm{s}^{-1}$

$V_{c z} \quad$ - volume of solid particle, $\mathrm{m}^{3}$

$\varepsilon \quad-$ bed porosity, -

$\varepsilon_{m f} \quad-$ bed porosity at minimum fluidising conditions, -

$\varepsilon_{0} \quad-$ porosity of stationary bed, -

$\mu_{g} \quad-$ dynamic viscosity, $\mathrm{Pa} \cdot \mathrm{s}$

$\xi^{g} \quad$ - Localloss coefficient, -

$\rho_{g} \quad-$ gas density, $\mathrm{kg} \cdot \mathrm{m}^{-3}$

$\rho_{s} \quad-$ solid density, $\mathrm{kg} \cdot \mathrm{m}^{-3}$

$\sigma \quad-$ thickness of the sieve plate, $m$

$\varphi \quad-$ shape factor, -

$\psi \quad-$ sphericity of particle, - 


\section{Introduction}

At the beginning of the twentieth century, Fritz Winkler discovered the phenomenon of fluidisation, observing that the movement of an air flow caused the bulk material to loosen and created a suspension in which the solid particles are in a chaotic motion. This initiated the very rapid development of fluid technology and its wide application in many industries. The main reason for this is a number of advantages of the fluidisation process, such as: significant intensification of the mass and heat exchange process through the use of very small sized particles of the dispersed phase, which results in extending the contact surface of the solid with the liquid without causing an increase in pressure loss; the possibility of carrying out the process on a continuous basis; thorough and rapid mixing, which makes the fluidised bed can be function as an isothermal system [1-3].

The most common unit operations performed in fluidised bed apparatus are solidification and granulation, coating, drying, adsorption and heat exchange processes. Fluid techniques also encounter difficulties such as: uneven residence time of particles in the reactor; the formation of disturbances causing heterogeneity of the fluidised bed; attrition of grains, walls of the apparatus and other elements placed in the bed; large complications related to the formation of clusters of particles and their sintering $[1,2]$. In order to solve some of these problems, various construction solutions are applied, both for the construction of the grate itself and for the whole apparatus; furthermore, it is important to exert as much control over the process as possible from the design stage using many correlations to determine the relevant optimal parameters.

The fluidisation process is a complex problem in which many physicochemical factors are taken into account, such as hydrodynamics of flow around solid particles, hydrodynamics of fluid flow through channels, heat exchange, and mass. This has generated a lot of interest from scientists and has prompted a multitude of works addressing many important issues in this area allowing further improvement and progress in the field of fluid technology applications $[1,2,4]$. Winkler has made the first attempt of the industrial application of fluid technology to gasifying coal in a moving bed [5]. The next step was made around 20 years later when the process of fluid catalytic cracking (FCC) was widely used. The similarity of the fluidised bed to the liquid made it possible to control losses of the catalyst, which up to now had been very quickly deactivated during cracking due to the accumulation of carbon particles [5]. Fluid technology has subsequent been applied in the Fisher-Tropsch process, in which it increases synthesis efficiency and extends the life of the catalyst; addionally, it has applications in polymerisation and metallurgy for such processes as roasting and calcination $[5,6]$. Other chemical reactions using a fluidised bed are partial oxidation, reforming of oil fraction and halogenation. Fluidisation is used in performing all thermal decomposition processes, such as: combustion (coal, biomass, waste), pyrolysis (coal, biomass), gasification of coal, biomass or plastic waste, and degassing.

Many advantages of fluidisation are widely exploited in the field of chemical and process engineering in a variety of physical processes $[1,5,7,8]$. The most popular applications of fluidisation technology include: 
- the purification and dedusting of waste gases in devices such as various types of scrubbers and fluidised filters - the absorption of pollutants in such apparatus is performed in three-phase systems (purified gas, liquid spraying, solid particles);

- heat exchange through fluid exchangers;

- drying-fluidised bed driers enable lower energy consumption than convection dryers and can be successfully used for drying various bulk materials (salt, cement, pharmaceutical products), pastes and sludges (sewage sludge), and secondary fuels (SRF);

- freezing - a cooled fluid stream receives heat from the frozen material, mainly food, such as fruits or vegetables;

- crystallisation - in the case of a fluidised bed crystalliser, it is possible to obtain a homogeneous product in terms of dimensions and crystals; during homogeneous fluidisation, almost perfect classification may occur - crystals of the largest size are organised at the bottom, while smaller crystals float at the top of the fluidised bed;

- sorting - classification of different particle sizes in the fluidisation process - the bed undergoes differentiation up the height of the apparatus with the heavier phases occupying the part of the column closer to the bottom and the lighter phases, consisting of smaller size particles or density, being lifted higher in up the column;

- disintegration and grinding of the material - turbulent movement of the solid causes its disintegration - this is used in fluidised jet mills;

- granulation - mainly used for the production of fertilisers in the form of granules (e.g. ammonium nitrate), for the production of catalysts used in the petrochemical industry, and for the production of various small food products (instant coffee, granulated tea) and pharmaceutical granules - this process can be performed in two ways by spraying the liquid on the surface of the particles or by the addition of a binder;

- coating (encapsulation) - performed in the same manner as granulation through the use of dry technology (binder addition) or wet technology (liquid drop dispersal) and used in the food and pharmaceutical industry;

- mixing.

The use of fluid technology enables increasing the efficiency of receiving the product while reducing production costs and emissions to the atmosphere. Meeting the restrictions imposed by the European Union is a fundamental challenge for the industry during the ecological era, which is why fluid technology is widely developed in combustion processes, where the emission level is the highest. Use of the liquefaction technique allows the simultaneous combustion and desulfurisation of fuels by bringing the appropriate sulphurbinding sorbents to the bed, and also reduces $\mathrm{NO}_{\mathrm{x}}$ emissions to the atmosphere (this process has a low combustion temperature of around $800-900^{\circ} \mathrm{C}$ ). In addition, the use of this type of furnace ensures a high rate of heat exchange in the furnace chamber and increases fuel combustion efficiency due to the thorough mixing and long residence time of particles in the bed, which results in the possibility of using smaller sized appliances and conducting the process at lower temperatures. The advantage of this application is also the possibility of using biomass, all kinds of enery-rich waste or low-grade coal with a high sulfur content as raw material. The popularity of this solution is already evident in global trends, where in 
recent years, many powerplants have started using fluidised bed furnaces. In 2008, the largest supercritical boiler with a circulating fluidised bed with a capacity of up to $460 \mathrm{MW}$ and powered with hard coal was commissioned at the Eagisza powerplant in Poland. Of course, this has not been in the leading position with regard to capacity for a long time, in recent years many other fluidised bed boilers have been put into use, in South Korea alone, one plant in 2015 produced four new devices, each with a capacity of $550 \mathrm{MW}[1,5,7-9]$.

\section{Theoretical section}

The fluidised bed occurs in a range of fluid velocities between the minimum fluidisation velocity and terminal velocity. In this range, pressure drops are assumed to be permanent. It is important to initially determine the characteristic velocity of the selected system in order to determine the fluidisation conditions corresponding to the considered process.

The minimum fluidisation velocity is the value describing the state in which the fluid overpressure equates with the pressure exerted by the bed, i.e. the minimum speed needed to disturb the stability of the stationary bed and start the fluidisation process. This moment presents the equation:

$$
\Delta p_{m f}=\left(1-\varepsilon_{m f}\right) \cdot g \cdot\left(\rho_{s}-\rho_{g}\right) \cdot H_{m f}
$$

When the bed parameters are known at the moment of minimum fluidisation, the Ergun formula can be used to calculate the minimum fluidisation velocity; this describes the dependence of the pressure drop in the bed on the fluidisation velocity:

$$
\frac{\Delta p}{H}=150 \cdot \frac{(1-\varepsilon)^{2} \cdot \mu_{g} \cdot u}{\varepsilon^{3} \cdot\left(\psi \cdot d_{p}\right)^{2}}+1.75 \cdot \frac{(1-\varepsilon) \cdot \rho_{g} \cdot u^{2}}{\varepsilon^{3} \cdot \psi \cdot d_{p}}
$$

After entering the number of $\operatorname{Re}$ and $A r$ into this equation and transforming it due to the conditions of the beginning of the fluidisation, we get:

$$
A r=150 \cdot \frac{\left(1-\varepsilon_{m f}\right)}{\varepsilon_{m f}^{3} \cdot \psi^{2}} \cdot R e_{m f}+1.75 \cdot \frac{1}{\varepsilon_{m f}^{3} \cdot \psi} \cdot R e_{m f}^{2}
$$

Equation (3) can be simplified for the appropriate flow range and after receiving the value of the Reynolds number, calculate the rate of fluidisation starting from it.

For laminar flow $\left(\operatorname{Re}_{m f}>20\right)$, the Ergun formula takes the form:

$$
A r=150 \cdot \frac{\left(1-\varepsilon_{m f}\right)}{\varepsilon_{m f}^{3} \cdot \psi^{2}} \cdot R e_{m f}
$$


And for turbulent flow $\left(R e_{m f}<1000\right)$ :

$$
A r=1.75 \cdot \frac{1}{\varepsilon_{m f}^{3} \cdot \psi} \cdot R e_{m f}^{2}
$$

There are a number of equations in the literature allowing the calculation of the velocity at the beginning of fluidisation that have been proposed by many authors; however, they are limited by some ranges of applicability and not all are suitable for selected operating conditions.

In case the porosity or sphericity is unknown, it is to use the experimental equations, for example:

Grace's correlation:

$$
R e_{m f}=\left(27.2^{2}+0.0408 A r\right)^{0.5}-27.2
$$

Wen and Yu correlation:

$$
R e_{m f}=\left(33.7^{2}+0.0408 A r\right)^{0.5}-33.7
$$

Thonglimp's correlation:

$$
R e_{m f}=\left(31.6^{2}+0.0425 A r\right)^{0.5}-31.6
$$

Unfortunately, the experimental equations can lead to certain errors and do not describe every type of deposit well [10].

A different way to calculate the minimum fluidisation velocity is to use the critical Reynolds number $R e_{k r}=R e_{m p}$, which calculated from its relationship with $A r$ also allows calculation of the approximate velocity at the beginning of fluidisation:

$$
R e_{m f}=R e_{k r}=1.08 \cdot 10^{-3} \cdot A r^{0.94}
$$

Pressure losses arise as a result of many reasons, such as: friction of the stream against the column wall, grains rubbing against each other and also friction between grains and the fluidising fluid, while the biggest influence here is the the issue of maintaining particles in a fluidised state. The pressure drop for the medium flowing through the material layer is defined by the formula [11]:

$$
\Delta p=(1-\varepsilon) \cdot g \cdot\left(\rho_{s}-\rho_{g}\right) \cdot H=\left(1-\varepsilon_{0}\right) \cdot g \cdot\left(\rho_{s}-\rho_{g}\right) \cdot H_{0}
$$

Many equations are known for which knowledge of the bed parameters at any point in the process is not necessary, for example: 
Gibilaro's equation (for laminar and turbulent motion) [12]:

$$
\frac{\Delta p}{H}=\left(\frac{17.3}{R e}+0.336\right) \cdot \frac{\rho_{g} \cdot u^{2}}{d_{p}}(1-\varepsilon) \cdot \varepsilon^{-4.8}
$$

Kozeny's equation (low values of Reynolds number) [13]:

$$
\frac{\Delta p}{H}=180 \cdot \frac{(1-\varepsilon)^{2} \cdot \mu_{g} \cdot u}{g \cdot \varepsilon^{3} \cdot d_{p}^{2}}=\frac{5 \cdot(1-\varepsilon)^{2} \cdot \mu_{g} \cdot u}{g \cdot \varepsilon^{3} \cdot\left(\frac{V_{c z}}{s_{c z}}\right)^{2}}
$$

Burke-Plummer's equation $(R e>1000)[4]$ :

$$
\frac{\Delta p}{H}=1.75 \cdot \frac{(1-\varepsilon) \cdot u \cdot \rho_{g}}{d_{p} \cdot \varepsilon^{3}}
$$

Lev's equation $(R e<20)[12]$ :

$$
\frac{\Delta p}{H}=\frac{200 \cdot \mu_{g} \cdot u \cdot\left(1-\varepsilon_{m f}\right)^{2} \cdot \varphi^{2}}{d_{p}^{2} \cdot \varepsilon_{m f}^{3}}
$$

Kozeny-Carman's equation:

$$
\frac{\Delta p}{H}=180 \cdot \frac{u \cdot \mu_{g} \cdot(1-\varepsilon)^{2}}{(d \cdot \Psi)^{2} \cdot \varepsilon^{3}}
$$

The terminal velocity is the velocity equal to the free falling velocity of the particles, the exceeding of which is equivalent to the end of the fluidisation process and exhaustion of the granular material from the reactor. It is therefore the maximum speed at which the fluidisation process can take place and is calculated from dependence:

$$
u_{o p}=\sqrt{\frac{4 \cdot d_{p} \cdot\left(\rho_{s}-\rho_{g}\right) \cdot g}{3 \cdot c_{D} \cdot \rho_{g}}}
$$

Another way to determine terminal velocity for a certain bed is to use the Archimedes and Laszczenko numbers [10]:

$$
A r=\frac{d^{3} \cdot\left(\rho_{s}-\rho_{g}\right) \cdot g \cdot \rho}{\mu^{2}}
$$




$$
\begin{gathered}
L y=\frac{A r^{2}}{(18+0.61 \sqrt{A r})^{3}} \\
u_{o p}=\sqrt[3]{\frac{L y \cdot\left(\rho_{s}-\rho_{g}\right) \cdot g \cdot \mu_{g}}{\rho^{2}}}
\end{gathered}
$$

\section{Experimental section}

\subsection{The bed material and the fluidising agent}

The research applied a porous fluidised bed - a type of quartz sand $\left(\mathrm{SiO}_{2}\right)$, a chemically inert material. The stationary bed had a height of $0.7 \mathrm{~m}$. The material according to the division of Geldart was classified in group D. The fluidising medium of the bed was air at an average temperature of $40^{\circ} \mathrm{C}$, which was experimentally determined during the tests. The basic parameters characterising the bed and air are presented in Table 1.

Table 1. Parameters of fluidising gas and bed material

\begin{tabular}{|c|c|c|}
\hline Parameter & Unit & Value \\
\hline \multicolumn{3}{|c|}{ fluidising gas - air } \\
\hline$\mu_{g}$ & $\mathrm{~Pa} \cdot \mathrm{s}$ & $1.927 \cdot 10^{-5}$ \\
\hline$\rho_{g}$ & $\mathrm{~kg} \cdot \mathrm{m}^{-3}$ & 1.129 \\
\hline Granular material - porous fluidised bed \\
\hline$\varepsilon$ & - & 0.364 \\
\hline$d_{p}$ & $\mathrm{~m}$ & $0.875 \cdot 10^{-3}$ \\
\hline$\rho_{s}$ & $\mathrm{~kg} \cdot \mathrm{m}^{-3}$ & 2629 \\
\hline$\varphi$ & - & 1.08 \\
\hline
\end{tabular}

\subsection{Research methodology}

In the first part of the research, a series of measurements was made for a column filled with granular material. The bed material was brought to a fluidised state by gradually increasing the linear velocity of the gas from $0 \mathrm{~m} \cdot \mathrm{s}^{-1}$ to $4 \mathrm{~m} \cdot \mathrm{s}^{-1}$ whilst simultaneously reading the pressure drops on the pressure gauge. In the next step, the above procedure was repeated in the opposite direction, i.e. the gas velocity was reduced from maximum to zero. In the second part of the research, the bed was removed and the pressure drops were measured in an empty reactor as a function of gas velocity. 


\subsection{Test stand}

The tests were preformed in a column with a circular cross section with a diameter D of $0.074 \mathrm{~m}$. The quantity of the particles in the the fluidised bed was controlled by filtering through sieves placed at the bottom and top of the column. The bottom sieve also served as a gas distributor. The parameters of the sieve are summarised in Table 2.

Table 2. Catalogue data regarding the sieve according to the manufacturer Ann-Filters [15]

\begin{tabular}{|l|c|c|}
\hline \multicolumn{1}{|c|}{ Parameter } & Unit & Value \\
\hline mesh size & $\mathrm{mm}$ & 0.65 \\
\hline diameter of the wire & $\mathrm{mm}$ & 0.3 \\
\hline width of the grid & $\mathrm{mm}$ & 1000 \\
\hline open area & $\%$ & 47 \\
\hline number of mesh pores per $1 \mathrm{~cm}$ & $\mathrm{~m} \cdot \mathrm{cm}^{-1}$ & 11 \\
\hline number of mesh pores per $1 \mathrm{~cm}^{2}$ & $\mathrm{~m} \cdot \mathrm{cm}^{-2}$ & 111 \\
\hline weight $1 \mathrm{~m}^{2}$ & $\mathrm{~kg}$ & 1.20 \\
\hline type of weave & - & woven \\
\hline type of material & - & stainless steel \\
\hline steel grade acc. AISI & - & AISI 304 \\
\hline
\end{tabular}

The general scheme of the fluidised bed reactor is shown in Fig. 1.

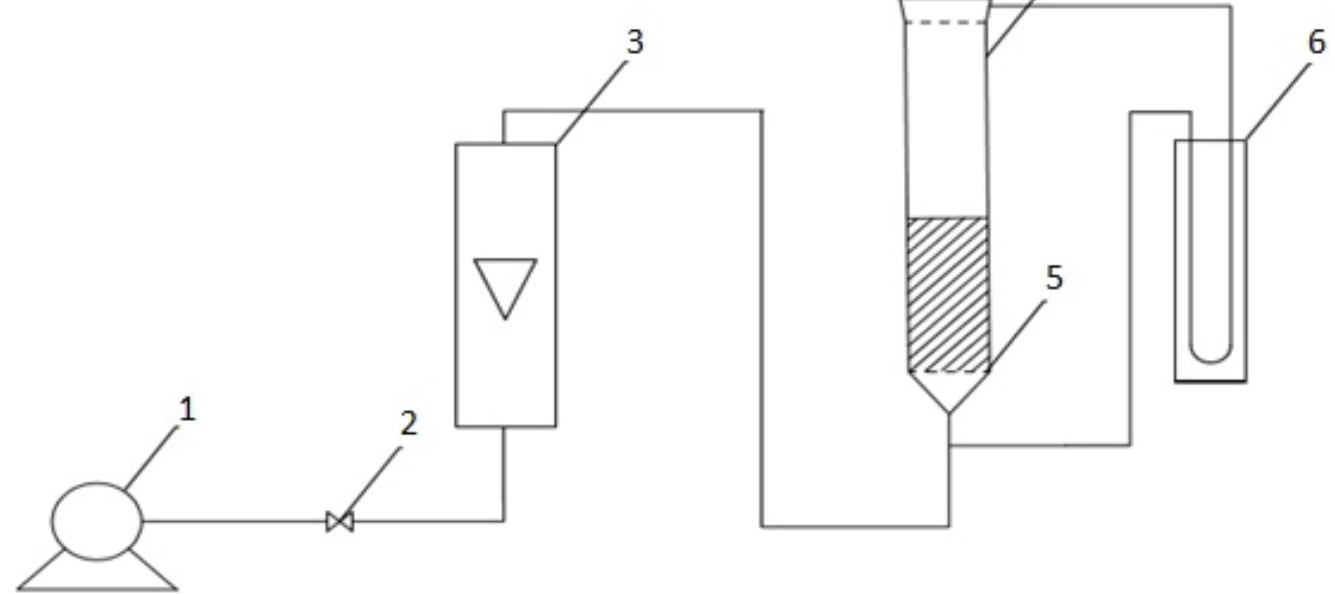

Fig. 1. Schematic diagram of the test installation: 1 - blower, 2 - regulating valve, 3 - rotameter, 4 - fluidisation column, 5 - gas distributor, 6 - water manometer [source: own material] 


\section{Results and discussion}

\subsection{Resistance of gas flow through a fluidised bed and an empty reactor}

The obtained curve (Fig. 2) is uncharacteristic of a fluidisation process. There was no stabilisation of pressure drops that are typical of fluidisation. While lowering the gas velocity, a higher flow resistance was recorded than when its velocity was increased. This is due to the polydispersity of the fluidised bed. For particles with a smaller diameter, the gas velocity exceeded the value of their free fall velocity sooner than in the case of the other particles. Therefore, they were exhausted from the bed and stopped by a sieve mounted at top of the column, thus creating additional resistance.

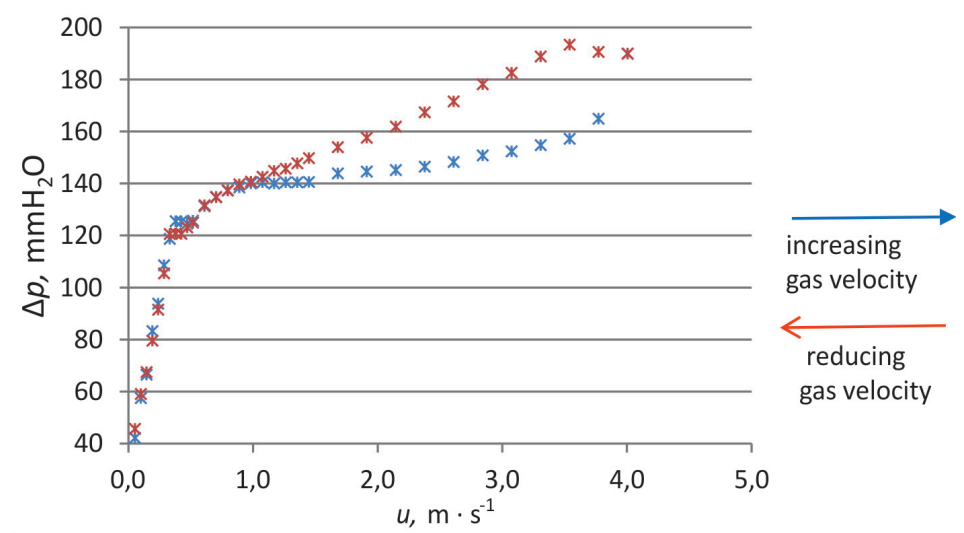

Fig. 2. Graphic representation of the dependence of the gas pressure drop in the fluidisation process on its velocity

After the second part of the research, an exponential increase in the resistance of gas flow through the empty reactor was observed along with the increase of gas velocity (Fig. 3).

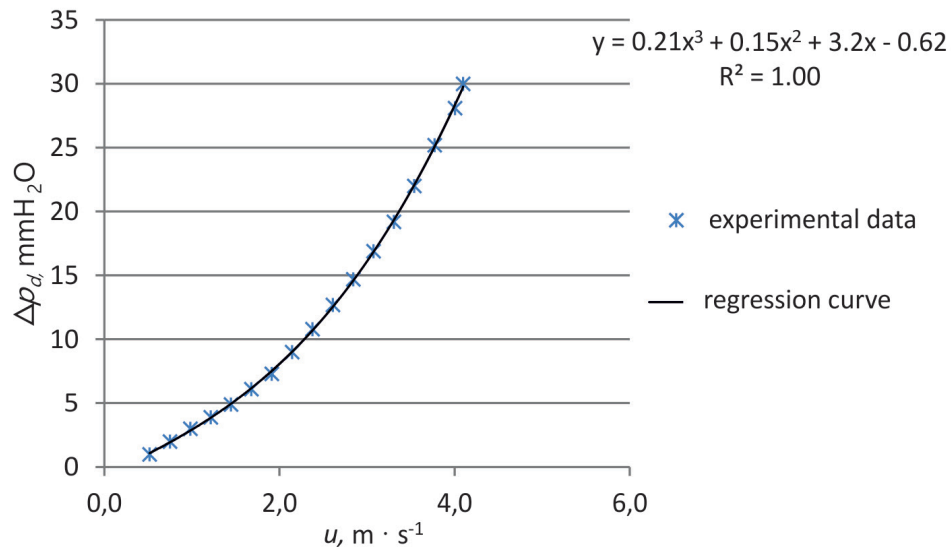

Fig. 3. Graphic representation of the dependence of the pressure drop in the empty column on the gas velocity 
When the pressure drops generated by the sieve plate and the sieve closing the reactor from the top were taken into account, a characteristic curve of only the working fluidised bed was obtained (Fig. 4); this was characterised by constant resistance to gas flow as its velocity increased. Initial fluctuations in the pressure drops may be due to an uneven material grain diameter; these grains were suspended at different velocities of the fluidising medium.

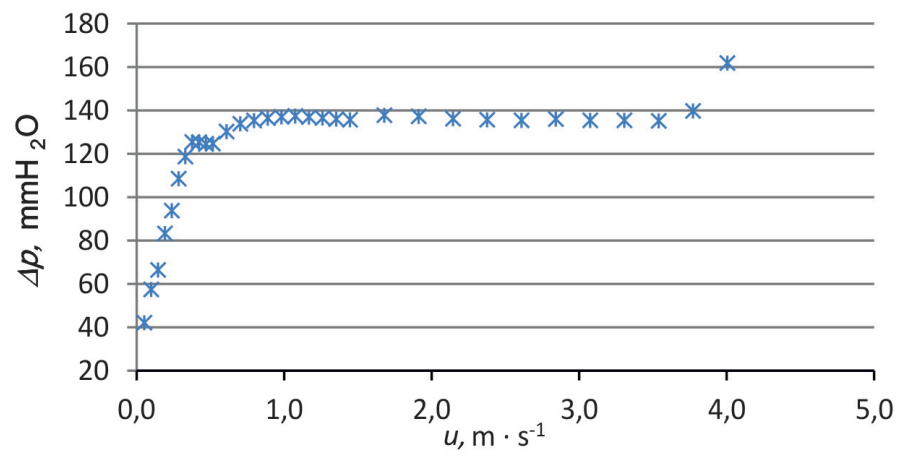

Fig. 4. Graphic representation of the dependence of the pressure drop in the fluidised bed on gas velocity

\subsection{Theoretical calculations of process parameters}

\subsubsection{Gas flow resistance in a fluidised bed}

Analysing the obtained experimental data, the approximate value of the minimum fluidisation velocity was determined as $u_{m f}=0.4 \mathrm{~m} \cdot \mathrm{s}^{-1}$. The average value of pressure losses generated by the fluidised bed was $\Delta p_{s r}=134 \mathrm{~mm} \mathrm{H}_{2} \mathrm{O}$. In order to assess the suitability of the equations of different authors in the literature to describe the hydrodynamics of the fluidised bed, the pressure drops for the experimental value $u_{m f}$ were calculated (Table 3 ).

Table 3. List of calculation results for pressure drops on the bed

\begin{tabular}{|c|c|c|c|c|}
\hline \multicolumn{2}{|c|}{$\Delta p$ calculated, $\mathrm{mmH}_{2} \mathrm{O}$} & \multirow{2}{*}{$\Delta p_{s \mathrm{r}}, \mathrm{mmH}_{2} \mathrm{O}$} & \multirow{2}{*}{$\begin{array}{l}\text { Absolute error, } \\
\qquad \mathrm{mmH}_{2} \mathrm{O}\end{array}$} & \multirow{2}{*}{ Relative error, \% } \\
\hline Author & Value & & & \\
\hline Ergun (2) & 120 & \multirow{5}{*}{134} & 14 & 11.7 \\
\hline Gibilaro (11) & 139 & & 5 & 3.6 \\
\hline Kozeny (12) & 155 & & 21 & 13.5 \\
\hline Kozeny-Carman (15) & 124 & & 10 & 8.1 \\
\hline Lev (14) & 138 & & 4 & 2.9 \\
\hline
\end{tabular}

By comparing the value of the average pressure drop during the actual fluidisation determined on the basis of experimental data with the losses obtained by theoretical calculations, it can be observed that the results are similar; however, not all give a satisfactory result. A certain error probably generates an inaccurate determination of the minimum 
fluidisation velocity on which the calculated pressure drop depends. In addition, the equations used are mainly empirical equations, so the values obtained with them may differ from the values obtained during this experiment. The correlations that best capture the dependence of the pressure drop on the gas velocity for the given operating conditions appear to be the Lev (14) and Gibilaro (11) equations.

\subsubsection{The minimum fluidisation velocity}

Using the known dependences of the velocity of the fluidising medium and the pressure drop on the bed, the critical velocity values for the average pressure drop determined on the basis of the experiment were calculated $\left(\Delta p_{s r}=134 \mathrm{~mm} \mathrm{H}_{2} \mathrm{O}\right)$. The results are summarised in Table 4.

Table 4. Set of theoretical calculations of critical speed for the tested bed

\begin{tabular}{|c|c|c|c|c|}
\hline \multicolumn{2}{|c|}{$\mathrm{m} \cdot \mathrm{s}^{-1}$} & \multirow{2}{*}{$u_{m \rho} \mathbf{m} \cdot \mathbf{s}^{-1}$} & \multirow{2}{*}{ Absolute error, $\mathbf{m} \cdot \mathbf{s}^{-1}$} & \multirow{2}{*}{ Relative error, \% } \\
\hline Author & Value & & & \\
\hline Ergun (2) & 0.48 & \multirow{4}{*}{0.4} & 0.08 & 16.7 \\
\hline Gibilaro (11) & 0.39 & & 0.01 & 2.6 \\
\hline Kozeny (12) & 0.49 & & 0.09 & 18.4 \\
\hline Kozeny-Carman (15) & 0.49 & & 0.09 & 4.8 \\
\hline
\end{tabular}

To obtain search velocity, the equation defining the Reynolds number and correlations binding the Reynolds number with the Archimedes number using appropriate constants were used [12]:

$$
R e_{m f}=\sqrt{C_{1}^{2}+C_{2} \cdot A r}-C_{1}
$$

Table 5. Summary of theoretical calculations of the critical velocity for the tested fluidised bed (constans $C_{1}, C_{2}:[12]$ )

\begin{tabular}{|c|c|c|c|c|c|c|c|}
\hline Author & $A r$ & $C_{1}$ & $C_{2}$ & $\boldsymbol{R} \boldsymbol{e}_{m f}$ & $\begin{array}{c}\boldsymbol{u}_{m \mathbf{f}^{\prime}} \\
\mathbf{m} \cdot \mathbf{s}^{-1}\end{array}$ & Absolute error, $\mathrm{m} \cdot \mathrm{s}^{-1}$ & Relative error, \% \\
\hline Wen and $\mathrm{Yu}$ & \multirow{6}{*}{52000} & 33.7 & 0.0408 & 24 & 0.46 & 0.06 & 13.0 \\
\hline Richardson & & 25.7 & 0.0365 & 25 & 0.49 & 0.09 & 18.4 \\
\hline Saxen Vogel & & 25.3 & 0.0571 & 35 & 0.68 & 0.28 & 41.2 \\
\hline $\begin{array}{l}\text { Babu and } \\
\text { others }\end{array}$ & & 25.25 & 0.0651 & 38 & 0.75 & 0.35 & 46.7 \\
\hline Grace & & 27.2 & 0.0408 & 26 & 0.52 & 0.12 & 23.1 \\
\hline Chitester & & 28.7 & 0.0494 & 30 & 0.58 & 0.18 & 31.0 \\
\hline
\end{tabular}


Comparing the critical speed values obtained by theoretical calculations, one can observe quite a large spread of results. The effect that most deviates from the real effect $\left(\delta u_{m f}=47 \%\right)$ is that resulting from the equation proposed by Babu. The dependencies of Chitester, Grace, Saxen and Vogel also do not work, which is probably due to a matter of the constants that were experimentally fitted by these researchers not being proper for the tested bed.

\subsubsection{Terminal velocity}

a) Calculation of the terminal velocity:

- from the equation to the free falling of solid particles (20):

$$
u_{t}=7.4 \mathrm{~m} \cdot \mathrm{s}^{-1}
$$

- from the relationship between the Archimedes and Laszczenko numbers described by equations (17), (18):

$$
u_{t}=5.5 \mathrm{~m} \cdot \mathrm{s}^{-1}
$$

- from the formula proposed by Gumz and Frössling for Reynolds numbers in the range of $3 \cdot 10^{2} \leq R e_{t} \leq 2.5 \cdot 10^{3}[16]$ :

$$
\begin{gathered}
\frac{1}{R e_{t}}=\frac{21.35}{\log \frac{\Psi}{0.065}} \cdot \frac{1}{A r}+\sqrt{\frac{2.593-2.382 \cdot \Psi}{A r}} \\
u_{t}=6.3 \mathrm{~m} \cdot \mathrm{s}^{-1}
\end{gathered}
$$

Results obtained by means of the above equations give quite diverse values of suspension speed; perhaps this is due to the origin of the equations. The first two are equations of theoretical origin; they refer to the calculation of the falling speed of a single particle, but they do not take into account the influence of the interaction of other grains or the sphericity of the particles. The equation of Gumz and Frössling is one of many empirical equations proposed to calculate the suspension velocity which does the impact of these factors take into account.

Fig. 4 shows the experimental data printed, it can be read that the suspension speed was approx. $u_{t}=4.0 \mathrm{~m} \cdot \mathrm{s}^{-1}$. During the tests, however, this speed was not observed. At the gas velocity value of $4.0 \mathrm{~m} \cdot \mathrm{s}^{-1}$ the bed remained in a state of fluidisation. A sudden drop in pressure could be caused by the lifting up of individual grains coming from the smallest fraction of material, which caused clogging of the upper sieve.

\subsubsection{Gas flow resistance at the distributor}

The equation showing the increasing dependence of pressure drops generated by the grate as a function of the speed of the fluidising medium $\Delta p_{d}=f(u)$ was adjusted (Fig. 3). This dependence can be determined with high accuracy using the following correlation [11]: 


$$
\Delta p_{d}=0.21 \cdot u^{3}+0.15 \cdot u^{2}+3.2 \cdot u-0.62
$$

a) Calculation of pressure drops on the sieve

Pressure drops on the sieve were calculated using:

- Pavlov's equation:

$$
\Delta p_{d}=\frac{0.503 \cdot u_{0}^{2} \cdot \rho_{g} \cdot\left(1-f^{2}\right)}{C^{2}}
$$

- Malakonov's equation:

$$
\begin{gathered}
\Delta p_{d}=\xi \cdot \frac{u^{2} \cdot p_{g}}{2 \cdot f^{2}} \\
\xi=1.75 \cdot(1-f)^{2} \cdot\left(\frac{d_{o}}{\delta}\right)^{2} \\
\xi=0.577
\end{gathered}
$$

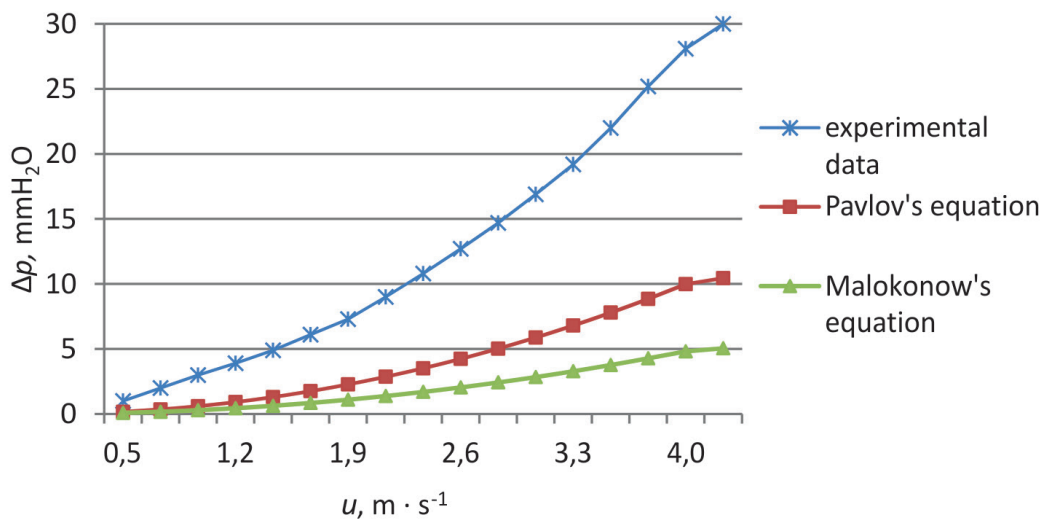

Fig. 5. A graph that summarises the results of theoretical calculations of pressure drops on a gas distributor with experimental data

Considering the results of pressure drops produced by the sieve plate, it can be concluded that the plate does not cause sufficient resistance to the gas flow. This resistance is simultaneously large enough to significantly affect the hydrodynamics of the process. According to the literature, a well-designed gas distributor should fulfill the dependence $\Delta p_{d}=(0.2-0.4) \cdot \Delta p$, to ensure process stability. The sieve used in the tests, due largely to the high clearance value (0.47), results in much lower pressure drops. This causes non-compliance of the experimental results with the values calculated using the formulas proposed by Pavlov and Molokonov. The Pavlov equation gives the value of the open area in the distributor plate as the value often accepted as $0.01-0.04$, which illustrates the deviation of the tested sieve 
from his equation (Fig. 5). As a result, unfortunately, none of the correlations used to calculate local pressure losses on the sieve led to results similar to the empirical results; therefore, it does not describe the work of the selected gas distributor well.

\section{Summary and conclusions}

For the tested air-solid system, the best equation for determining the pressure drops occurring in the fluidisation state was the equation proposed by Gibilaro (11). When taking into account critical velocity, it is also the dependence given by Gibilaro that yields the best result. This gives valuable information that it is the equation that best describes the dependence between pressure drops and gas velocity for the tested bed. This is the case for fluidised bed and takes into account the losses caused by the pore size and the occurrence of contraction [4].

An important issue in the application of fluid technology, which is well illustrated by the results of the experiment, is the control of the grain size of the layer material. A bed with a given, representative value of the particle diameter contains finer fractions. Even a small difference in grain size affects the hydrodynamic parameters of the system, causes clogging of the upper sieve and uncontrolled pressure drops and material loss.

The sieve used in the tests has a significant influence on the gas flow resistance through the fluidisation reactor, despite the high clearance value (0.47). The effect of this resistance should be taken into account at the design stage of the fluidisation apparatus. Of the equations that are presented in the paper showing gas pressure drops as a function of its velocity on the distributor, neither those of Molokonow nor those of Pavlov describe the operation of the tested sieve to a satisfactory level of accuracy.

\section{References}

[1] Dziubiński M., Prywer J., Mechanika plynów dwufazowych, WNT, Warszawa 2009.

[2] Razumow I.M., Fluidyzacja i transport pneumatyczny materiałów sypkich, WNT, Warszawa 1975.

[3] Kowarska B., Spalanie paliw alternatywnych $w$ reaktorze fluidyzacyjnym $z$ obnizeniem emisji tlenków azotu, Politechnika Krakowska, Kraków 2015.

[4] Kmieć A., Englart S., Ludwińska A., Teoria i technika fluidyzacji, Oficyna Wydawnicza Politechniki Wrocławskiej, Wrocław 2007.

[5] Berkowicz G., Synteza 2,6-dimetylofenolu we fluidalnym złożu katalizatora żelazowo-chromowego, rozprawa doktorska, Politechnika Krakowska, Kraków 2015.

[6] Fluidization, https://en.wikipedia.org/wiki/Fluidization (access: 3.12.2017).

[7] Krystalizacjaifluidyzacja, praca zbiorowa, red. nauk.Jadwiga Rodzynkiewicz-Rudzińska, WNT, Warszawa 1973. 
[8] Kmieć A., Zastosowanie i modelowanie procesów i aparatów ze złożem fluidalnym, Oficyna Wydawnicza Politechniki Wrocławskiej, Wrocław 2012.

[9] Strumiłło C., Podstawy teorii i techniki suszenia, wyd. 2 zm. i roz., WNT, Warszawa 1983.

[10] Ćwiczenia laboratoryjne $z$ inżynierii chemicznej. Skrypt dla studentów wyższych szkót technicznych, praca zbiorowa, Politechnika Krakowska im. Tadeusza Kościuszki, Kraków 1979.

[11] Pawłow K.F., Romankow P.G., Noskow A.A., Inżynieria Chemiczna. Przykłady i zadania z zakresu aparatury i inżynierii chemicznej, WNT, Warszawa 1969.

[12] Iwanowski J., Badanie i modelowanie kinetyki suszenia fluidalnego wybranych ciat stalych, rozprawa doktorska, Politechnika Krakowska, Kraków 2011.

[13] Yang W.-C., Handbook of fluidization and fluid-particle systems, Marcel Dekker, New York 2003.

[14] Procesy kontaktowania faz, http://slideplayer.pl/slide/423669/ (access: 4.01.2018).

[15] Ann-Filters Poland, https://siatkifiltracyjne.com.pl/ (access: 4.01.2018).

[16] Ciborowski J., Podstawy inżynierii chemicznej, WNT, Warszawa 1965. 